\title{
9
}

\section{Preparing Today's Faculty for Tomorrow's Students: One College's Faculty Development Solution}

\author{
Patrick Nellis \\ Helen Clarke \\ Jackie DiMartino \\ David Hosman \\ Valencia Community College
}

Valencia Community College in Orlando, Florida, has created a faculty development program undereritten for the past five years by a US Department of Education Title III Strengthening Institutions Grant. Our program rose from a deliberate desire to build active, collaborative faculty teams that would, in turn, build active, collaborative classrooms; our results demonstrate that faculty development programs based on observable and measurable outcomes can positively affect student academic performance and persistence. This essay details this faculty development project.

\section{Our Beginnings}

Since its origin, the American community college movement has fought to keep the door open to students who have traditionally been refused admission into higher education. A major concern remains that the typical community college freshman does not possess the tools needed to succeed in college. Although we have afforded them access to higher education, we have often neglected to equip them with the essential tools for success in the academy. At Valencia Community College in Orlando, Florida, we have found that a dynamic and structured faculty 
development program can have a positive impact on student performance. We based our program on the wealth of current literature on learning and curriculum development theory. The most important component in the implementation of our program was using the principles of active and collaborative learning. We modeled the classroom techniques faculty participants later used in their own teaching practice.

Faculty development at Valencia has taken many directions. The college has made attempts at professional development over the past 30 years, from reimbursement for workshops and conferences to the occasional external consultant. Recently, the institution has established an ongoing series of brief seminars offered to a wide variety of faculty and staff about a myriad of topics, including campus safety, retirement planning, legal issues in hiring, and so on. A small number of seminars have been directly related to curriculum, teaching, or learning. However, at $\mathrm{Va}$ lencia, a systematic faculty development effort has been underway for the past five years, underwritten by a US Department of Education Title III Strengthening Institutions Grant. Through this process, we learned much about designing and implementing a faculty development program. The program grew out of Valencia's need to redevelop its curriculum (Gianini and Todd, 1995); we saw this as an opportunity to establish a well-planned faculty development program. To meet our challenge, we created a symbiotic relationship between curriculum and faculty development. Our faculty participants expanded their teaching skills and abilities while collaboratively redesigning courses. A unique outcome of our pedagogical diversity is that we have created a comprehensive model for faculty development [see Figure 9.1]. This model should prove to be particularly useful since Valencia, a comprehensive community college serving students over a three-county metropolitan area, shares similar challenges with many in the higher education community.

We began designing our faculty development program with the daunting reality that $90 \%$ of our 5,000 annual FTIC (first time in college) students were mandated into developmental reading, writing, and/or mathematics courses as measured by the College Placement Test (CPT). Retention, persistence, and completion rates of those students were at or below the national averages according to data analysis conducted by Valencia's Office of Institutional Research conducted in 1998. We believed we could effect positive change in the performance of all students by enhancing the teaching skills of the faculty and the learning skills of the students. While much has been accomplished in terms of improved teaching through a focus on active learning, we also saw the need to tie 
FIGURE 9.1

\section{PROGRAM OUTLINE}

\begin{tabular}{|l|l|}
\hline $\begin{array}{l}\text { OUTCOMES / PRODUCTS } \\
\text { What do you want faculty to } \\
\text { be able to do as a result of this } \\
\text { program? }\end{array}$ & $\begin{array}{l}\text { Performance-based course outcome summaries } \\
\text { Specific learning and retention strategies } \\
\text { (best practices) } \\
\text { Course manuals for students } \\
\text { Course manuals for adjunct professors }\end{array}$ \\
\hline $\begin{array}{l}\text { CONTENT } \\
\text { What do you want faculty to }\end{array}$ & $\begin{array}{l}\text { Critical thinking } \\
\text { Diversity/inclusion } \\
\text { Developmental advising } \\
\text { Assessment }\end{array}$ \\
\hline $\begin{array}{l}\text { PROCESSES } \\
\text { learn? }\end{array}$ & $\begin{array}{l}\text { Collaborative learning among peers } \\
\text { Guided readings and seminars (face-to-face and } \\
\text { online dialog) }\end{array}$ \\
$\begin{array}{l}\text { Consultant presentations and topical workshops } \\
\text { Practice teaching, peer observation } \\
\text { Design, test, publish results }\end{array}$ \\
\hline $\begin{array}{l}\text { RESOURCES to } \\
\text { What will faculty need to sup- } \\
\text { port learning? }\end{array}$ & $\begin{array}{l}\text { Faculty release times, faculty stipends } \\
\text { Consultants, materials } \\
\text { Management, staff } \\
\text { (funded internally and by grants) }\end{array}$ \\
\hline $\begin{array}{l}\text { WTRUCTURES } \\
\text { Whark will the program need? }\end{array}$ & $\begin{array}{l}\text { Project-based (a course or a significant module) } \\
\text { Team-based (not committee work; more than } \\
\text { workshops) } \\
\text { Managers, leaders, design team participants }\end{array}$ \\
\hline $\begin{array}{l}\text { Qualitative and quantitative } \\
\text { Data on pilot test of course design: retention } \\
\text { and achievement }\end{array}$ \\
\hline
\end{tabular}

classroom activities to the specific learning goals of a course, as well as to the overall competencies of a Valencia graduate [see Figure 9.2]. This approach to course design is sometimes referred to as "outcomes-based instruction" or "performance-based instruction" (PBI), the term we use at Valencia.

We have recently focused our course redesign efforts on the college preparatory (pre-college credit courses) area and expanded our impact by involving more faculty and staff, thereby increasing the number of students affected by the pilot sections college-wide. We remain serious about offering students real access to quality higher education, and our 


\title{
VALENCIA'S STUDENT CORE COMPETENCIES
}

\begin{abstract}
Valencia's student core competencies are complex abilities that are essential to lifelong success. These general competencies can be applied in many contexts and must be developed over a lifetime. They specify how learning can be expressed and assessed in practice. They enable students and faculty to set learning goals and assess within and across the many disciplines of human inquiry.
\end{abstract}

\section{THINK}

\section{TO THINK, WHAT MUST YOU DO?}

- Analyze data, ideas, patterns, principles, perspectives

- Employ the facts, formulas, procedures of the discipline

- Integrate ideas and values from different disciplines

- Draw well-supported conclusions

- Revise conclusions consistent with new observations, interpretations, or reasons

\section{HOW AND WHERE MUST YOU THINK?}

- With curiosity and consistency

- Individually and in groups

\section{COMMUNICATE}

TO COMMUNICATE, WHAT MUST YOU DO?

- Identify your own strengths and need for improvement as a communicator

- Employ methods of communication appropriate to your audience and purpose

- Evaluate the effectiveness of your own and others' communication

\section{HOW AND WHERE MUST YOU COMMUNICATE?}

- By speaking, listening, reading, and writing

- Verbally, nonverbally, and visually

- With honesty and civility

- In different disciplines and settings

\section{VALUE}

\section{TO VALUE, WHAT MUST YOU DO?}

- Recognize values as expressed in attitudes, choices, and commitments

- Distinguish among personal, ethical, aesthetic, cultural, and scientific values

- Employ values and standards of judgement from different disciplines

- Evaluate your own and others' values from individual, cultural, and global perspectives

- Articulate a considered and self-determined set of values

\section{HOW AND WHERE MUST YOU VALUE?}

- With empathy and fair-mindedness

- Individually and in groups

\section{$\mathrm{ACT}$}

\section{TO ACT, WHAT MUST YOU DO?}

- Apply disciplinary knowledge, skills, and valucs to educational and career goals

- Implement effective problem solving, decision-making, and goal-setting strategies

- Act effectively and appropriately in various personal and professional settings

- Assess the effectiveness of personal behavior and choices

- Respond appropriately to changing circumstances

\section{HOW AND WHERE MUST YOU ACT?}

- With courage and perseverance

- Individually and in groups

- In your personal, professional, and community life 
faculty development program is at the heart of our college-wide transformation into a more learning-centered college. The data on student performance, reported later in this article, are encouraging and give reason to believe that we now have the ability to keep our promise of educational access.

\section{The Framework}

Our efforts have focused on general education curriculum and have produced courses and teaching improvements resulting in improved student outcomes. The changes have begun to shift the entire college from teacher-centered to learner-centered where both teacher and student actively participate in learning. The program has enabled the faculty to do the following:

1) Renew connections to their disciplines

2) Participate in a campus academic culture that helps build connections between faculty members and across disciplines

3) Understand that underprepared students require developmental education prior to entering college-level courses

4) Evaluate and change curricula, including individual courses

5) Establish an inclusive learning environment that meets the needs of a diverse student body

6) Create a new paradigm where the students' learning potential and progress are maximized using active learning experiences

To meet these goals, Valencia's faculty development effort, managed by a program director, is supported by a full-time faculty development staff of four and two administrative assistants. Annually, 24 faculty members comprise the core of the curricular design team leadership. They, in turn, guide an additional 60 faculty and staff design team participants. Figure 9.3 depicts the structure of the program's personnel organization for one of four discipline areas.

The management team selects faculty leaders and co-leaders during the preceding summer. Faculty leaders are reassigned $50 \%$ of their time to faculty development activities and co-leaders receive a $\$ 2,200$ stipend. During the fall term, faculty leaders and co-leaders with primary responsibility for the curricular and instructional innovations participate in 


\section{FIGURE 9.3}

\section{Personnel Organization}

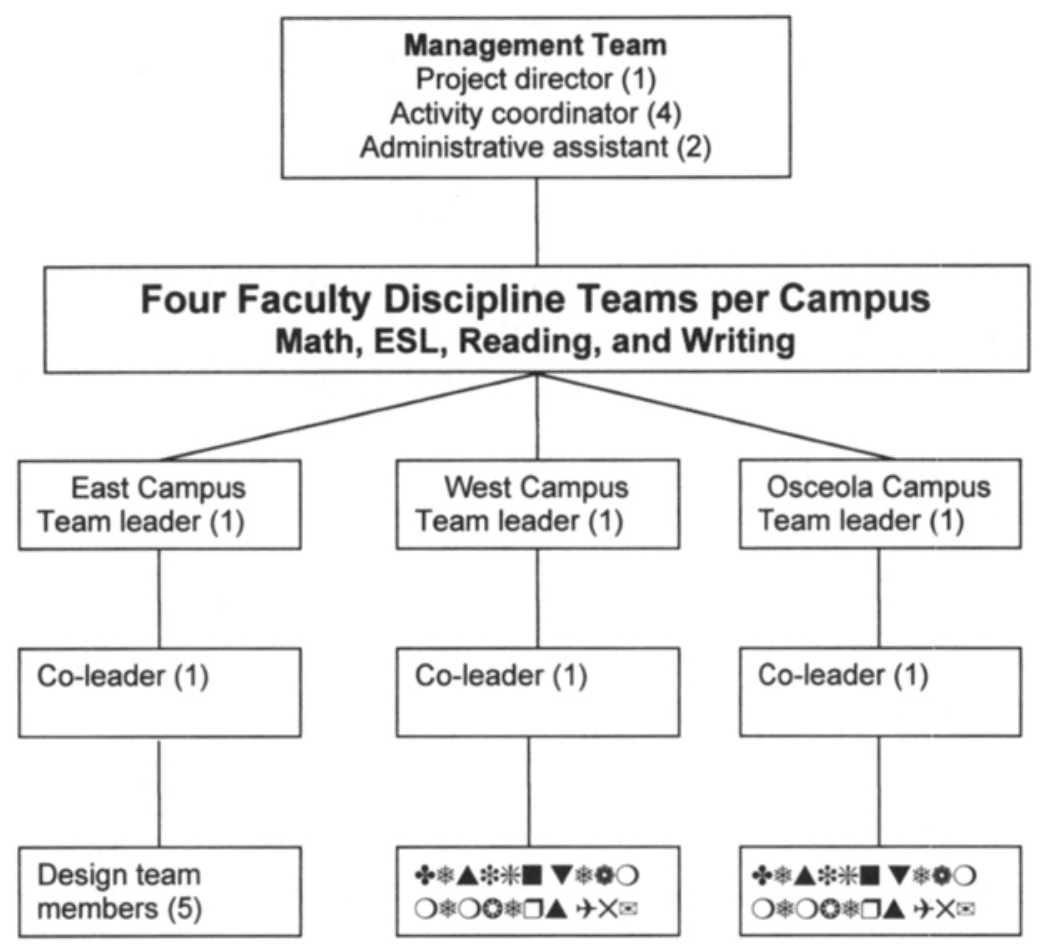

seminars, workshops, and online discussions facilitated by the management team. A variety of topics are addressed which pertain to enhancing student mastery of Valencia's competencies [see Figure 9.2]. Some of the reading list and consultants are selected by the management team, and some room for negotiating topics of interest is held for discussion with the new faculty leaders. Concurrently, the faculty leaders and co-leaders identify courses for redesign and related projects that they wish to pursue in the spring semester.

A group of additional faculty members is selected for the spring semester to work on discipline area design teams. Each faculty leader selects design team members. They then begin 60 hours of training, research, curriculum-development activities, workshops, and course revision/development. Design team members receive a $\$ 1,100$ stipend for their work. The newly expanded design teams help bring the team's goals into reality. Each design team redesigns course(s), including teaching strategies, accompanying materials, and assessments for implementation in a pilot sec- 
tion in the following academic year. The summer term is devoted to faculty development participants producing final products for the fall and conducting workshops for the at-large faculty. Finally, during the following fall term, faculty pilot-test their courses and ideas. The management team orchestrates the collection of student and instructor performance data. Figure 9.4 depicts the cycle of Valencia's faculty development program.

\section{From Telling to Doing: WORKING WITH Faculty as Learners}

The intention of our faculty development process has been to mirror desired outcomes. That is, we want our faculty to move from telling students about subjects to having the students doing a variety of things to demonstrate what they know and what they have learned. We have had to create a process for our faculty to do the projects that would show that they had internalized and could apply the best practices for improving student learning. Since we wanted our faculty to create performancebased instruction for their students, we have modeled our faculty development program on the principles of performance-based instruction (PBI).

Performance-based instruction asks the designer of learning experiences to consider two questions carefully:

1) What will the student be able to do?

2) How will we be able to know that they can actually do it?

The emphasis is not on knowledge recall or content per se, but on student performance. At the end of a learning experience, some level of competent or valuable student ability must be demonstrated. To facilitate PBI course design, we utilize the Wisconsin Instructional Development System (WIDS) [see Appendix 9.1], a software database management program. This program links student performance outcomes to the stated course competencies and to the overall competency goals of a Valencia graduate. Taking the PBI perspective seriously constitutes a shift in emphasis in higher education, with vast implications for everything we do as faculty and faculty developers, not the least of which is the design and delivery of instruction (O'Banion, 1997).

The management team has created a variety of engaging learning activities for our faculty, but in the spirit of PBI, each activity has been 
FIGURE 9.4

Faculty Development Cycle
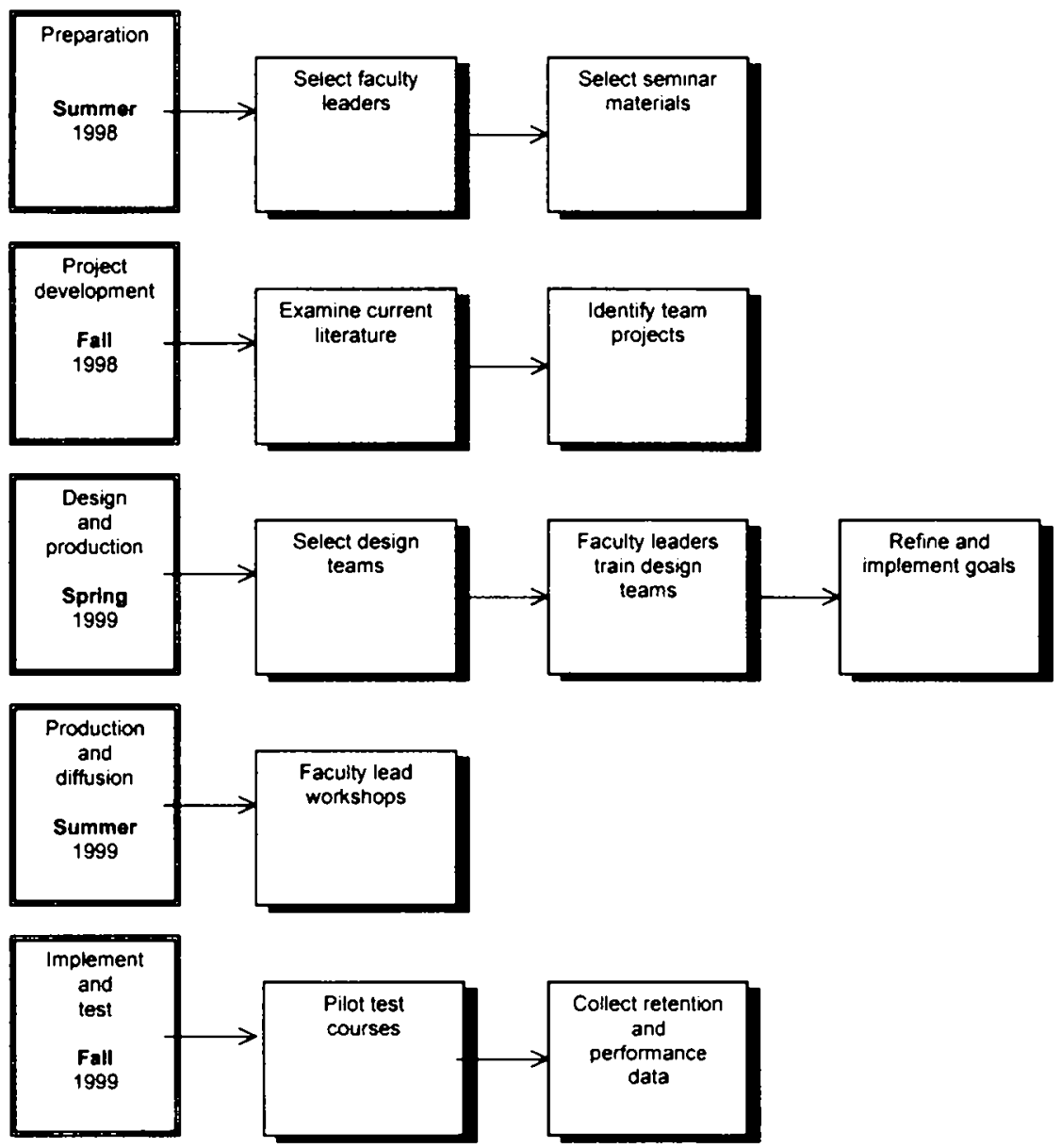

consciously employed to build toward the learning and performance outcomes of the faculty development program. Of course, we know the vital importance of practical, challenging, and interesting learning activities for faculty development workshops. The difference here has been, rather than offer isolated workshop activities, we have connected each learning experience to the desired and measurable outcomes of the faculty development program (as outlined in Figure 9.1).

Likewise, one major goal for faculty development is that participants 
create a course outline in which the learning activities for students are connected to measurable course outcomes. The management team establishes the conditions under which the faculty can apply their knowledge of PBI to this task. This is essentially a critical thinking process by which the faculty participants analyze what they do with students and why they do it. To write a PBI summary for their individual course designs, faculty participants construct activities around issues of pedagogy, discipline-specific content, and critical thinking itself, as both an outcome and as a method of instruction.

Early in the fall semester of each year, faculty engage in learning activities centered on critical thinking. Using the seminar method modeled after the Washington Center for Improving the Quality of Undergraduate Education, we structure seminars based on academic inquiry, often an all too rare experience outside the context of graduate school. Face-toface seminars continue throughout the faculty development program based on a variety of texts. Each seminar is extended via an online conferencing system, CAUCUS, that permits team members to reflect on the seminar and return to the reading to post comments that further the group's understanding of the topic's complexities. A follow-up meeting typically has the structure of a workshop, rather than a seminar, where members apply the concepts to their project.

Following a seminar on a key text for course design, faculty participants then identify the core concepts of a particular course. This leads to a concept mapping exercise where participants visually explicate the concepts and processes associated with mastery of a specific core concept. Because this activity is often challenging, we use cooperative learning formats with the faculty as a source of support for the exercise. As an avenue to learning PBI, faculty members write course outcomes based on student performance. For example, the remedial reading team rewrote a course goal from "understand main idea," a comprehension-level skill to "critique literal meaning from reading passages," a student performance more congruent with synthesis-level college reading requirements. The content of courses must be reconceptualized in terms of the students thinking and doing something observable and measurable with the content.

Our approach to each outcome has centered on active and cooperative learning. We have consciously applied Kolb's (1984) experiential learning model by varying the activities and modes from concrete to reflective to abstract to application. Most important, these activities have been clearly tied to enhancing faculty participants' ability to create the 
PBI course summary that guides the teaching and learning process during the pilot test of their redesigned courses. In our faculty development program, we have moved from topics like critical thinking or learning style theory to a variety of activities that foster the internalization of the content and its classroom application. We take assessment seriously for both the course design and the program itself. We incorporate formative and summative assessments throughout our program.

\section{Uncovering the Content}

While our program has not been driven by a set of topics to cover, our work does have a specific content, the core of which is captured by the four key concepts: 1) critical thinking, 2) diversity/inclusion, 3) developmental advising, and 4) assessment. Our identification of these four topics reflects both the needs and priorities of the college. The interrelation of these key concepts is clearly unavoidable. We have found that although analytically distinct, they frequently overlap in the practice of faculty development and by extension, teaching. Figure 9.5 identifies the curricular components of the faculty development program:

FIGURE 9.5

PROGRAM CONTENT

\begin{tabular}{|c|l|l|}
\hline \multicolumn{1}{|c|}{ TOPIC } & \multicolumn{1}{|c|}{ KEY CONCEPTS } & KEY ISSUES/QUESTIONS \\
\hline $\begin{array}{c}\text { Critical thinking } \\
1\end{array}$ & $\begin{array}{l}\text { Elements of thinking } \\
\text { Intellectual standards } \\
\text { Developmental stages }\end{array}$ & $\begin{array}{l}\text { Content = thinking } \\
\text { Recall is not knowledge } \\
\text { Fostering growth }\end{array}$ \\
\hline $\begin{array}{c}\text { Diversity } \\
2\end{array}$ & $\begin{array}{l}\text { Motivation } \\
\text { Culture } \\
\text { Construction of knowledge } \\
\text { Learning styles }\end{array}$ & $\begin{array}{l}\text { Establishing inclusion } \\
\text { Developing attitude } \\
\text { Seeking broader truths } \\
\text { Responsive teaching }\end{array}$ \\
\hline $\begin{array}{c}\text { Developmental } \\
\text { advising }\end{array}$ & $\begin{array}{l}\text { Rapport building } \\
\text { Life and career goals }\end{array}$ & $\begin{array}{l}\text { Learning styles } \\
\text { Academic plan }\end{array}$ \\
\hline Assessment & $\begin{array}{l}\text { Classroom assessment } \\
\text { techniques } \\
\text { Course embedded assessment } \\
\text { College core competencies }\end{array}$ & $\begin{array}{l}\text { Broad, classroom-based } \\
\text { group strategies } \\
\text { Focused, one-on-one } \\
\text { advising meetings }\end{array}$ \\
\hline
\end{tabular}


Performance-based instruction is not listed as a topic because it is the master concept for the whole set of content topics. All of our work is designed under the PBI model. Additionally, active and cooperative learning are more logically at the level of teaching strategies and are therefore not considered separate topics. While they are foundational and must be learned, they are actually methods which support the goals of critical thinking, diversity, developmental advising, and assessment rather than coequal topics in their own right. Technology, pictured as a watermark, overlays the chart because the use of technology is incorporated throughout our work, from PowerPoint, to Internet, to WIDS, to Valencia's customized advising software, Cyber Adviser.

\section{Outcomes}

The outcomes were in three major areas: 1) curricular designs and products created by faculty participants, 2) student academic performance in courses taught by faculty participants, and 3) persistence rates of students in pilot courses. Research databased on pilot courses taught by faculty participants show remarkable improvement in student performance.

Table 9.1 shows data from our most recent set of pilot courses taught during fall semester 1998 . The student passing rates with a grade of $\mathrm{C}$ or better and the student retention rates (reenrollment for the next semester) are higher for the redesigned pilot courses than for the nonpilot courses, in both college preparatory and college level.

TABLE 9.1

Results of Pilot Courses

\begin{tabular}{lcc}
\hline & $\begin{array}{c}\text { Passing Rate } \\
\text { (with } \mathrm{A}, \mathrm{B}, \text { or } \mathrm{C})\end{array}$ & $\begin{array}{c}\text { Retention } \\
\text { (re-enrollment Rate) }\end{array}$ \\
\hline $\begin{array}{l}\text { College preparatory (remedial) courses } \\
\text { Pilot }(\mathrm{N}=187)\end{array}$ & $68 \%$ & $78 \%$ \\
$\quad$ Nonpilot $(\mathrm{N}=4840)$ & $56 \%$ & $69 \%$ \\
College level general education courses & & \\
$\quad$ Pilot $(\mathrm{N}=648)$ & $69 \%$ & $75 \%$ \\
Nonpilot $(\mathrm{N}=4617)$ & $66 \%$ & $66 \%$ \\
\hline
\end{tabular}

The college preparatory courses included reading level 2, writing level 2, and mathematics level 1. The college-level courses included English composition level 2, Spanish at all 3 levels, and a variety of humanities courses. 
Our faculty development program for the 1998-99 year was exclusively focused on college preparatory courses in reading, writing, mathematics, and English as a Second Language. This was in response to a crisis in remedial education at our college and an acknowledgment of the successful pilot-tested designs that we have fostered over the past three years. Table 9.2 shows the pilot tests in several remedial areas that have increased student performance:

TABLE 9.2

Passing Rates in Pilot Courses

Pilot Courses in College Prep

(Remedial)

Reading $2(\mathrm{~N}=286)$ fall 1996

Writing $2(\mathrm{~N}=162)$ fall 1996

ESL $2(N=31)$ fall 1996

Math $1(\mathrm{~N}=109)$ fall 1997

Math $2(\mathrm{~N}=100)$ fall 1997
Improved Passing Rate

over non-pilot course

$15 \%$ higher than reading 2 previous semester $15 \%$ higher than writing 2 previous semester $21 \%$ higher than ESL previous semester $7 \%$ higher than math 1 previous semester $26 \%$ higher than math 2 previous semester

These measures of student performance in terms of passing rates and retention indicate the success of Valencia's faculty development program. We have also collected data on the faculty themselves. The following table is based on a sample of 12 faculty members who have been involved in the faculty development program over the past five years and shows the average improvement in their teaching performance after participating in the program:

TABIE 9.3

Teaching Performance

\begin{tabular}{lcc}
\hline & Student Passing Rates & Student Retention Rates \\
\hline $\begin{array}{l}12 \text { faculty participants } \\
\text { After at least one year of } \\
\text { faculty development }\end{array}$ & $15 \%$ increase on average & $10 \%$ increase on average \\
\hline
\end{tabular}

We also conducted a survey on a random sample of all full-time, college-wide faculty and staff. The survey instrument was designed to measure, on a Likert scale, faculty awareness and use of various teaching, learning, and advising strategies such as active learning, cooperative learning, and developmental advising. The respondents were grouped into three categories: 1) no involvement in faculty development, 2) one 
year of involvement in faculty development, 3) more than one year involvement in faculty development. The results showed that group 1 (no involvement) self-reported higher levels of use of these strategies than their level of awareness. Group 2 (one year of involvement) showed higher marks on both use and awareness than group 1, and the two indicators were nearly equal to each other. Group 3 (more than one-year involvement) showed the highest rating of use and of awareness, but faculty indicated that they were higher in awareness of the strategies than in their actual use of them with students. These findings are not surprising when one takes a developmental perspective: the more one learns about the complexities of cooperative learning, for example, the more selfcritical (or modest) one becomes when claiming a high level of implementation. By the same token, faculty members with little or no faculty development experience, as in the case with Group 1, they tend to overestimate their skills in an area of low awareness. Indeed, we often see this with student developmental inventories.

Another survey was conducted among all participants in the faculty development program over all five years. Of 200 faculty participants surveyed, 60 provided usable responses. Respondents overwhelmingly showed that they had indeed implemented curricular changes, made use of developmental advising techniques within the classroom, and taken steps to foster a more inclusive classroom. Fifty-five of 60 faculty felt that they had a deeper understanding of the content of the program. Based on four years of data collection, including these findings, we are confident that faculty who work within our program to redesign instruction contribute to higher levels of student learning.

Few studies focus on the relationship between faculty development programs and student outcomes or retention; even though, ". . . . both within and among colleges, faculty lack opportunities to learn from one another at precisely the moment when increasing communication among a diverse faculty has become a necessity" (Gabelnick et al., 1990, p. 7). However, surveys done by Gaff (1991) find that institutions with major faculty development programs did experience success in their student, faculty, and institutional outcomes.

\section{Conclusion}

In response to Boyer's (1987) observation that faculties are discouraged by inadequate support for intellectual pursuits at their institutions, he 
(1990) and other leaders in education have long called for academic attention to include teaching methods, learning theory, and classroom research. Our work at Valencia Community College shows that a comprehensive faculty development program, based on observable and measurable outcomes, positively affects student achievement and retention. The results demonstrate that this major change has positively affected student academic performance and persistence. Encouraging our faculty at Valencia to create improved learning opportunities for students has been both exciting and rewarding. Our program arose from a deliberate desire to build active, collaborative faculty teams who would, in turn, build active, collaborative classrooms reflecting both the needs and priorities of the college. We are encouraged as we continue this process.

\section{REFERENCES}

Belenky, M. F., Clinchy, B. M., Goldberger, N. R., \& Tarule, J. M. (1986). Women's ways of knowing: The development of self, voice, and mind. New York, NY: Basic Books.

Boyer, E. (1987). College: The undergraduate experience in America. New York, NY: Harper \& Row.

Boyer, E. (1990). Scholarship reconsidered: Priorities of the professoriate. Princeton, $\mathrm{NJ}$ : The Carnegie Foundation for the Advancement of Teaching.

CAUCUS. (1995). [Computer software]. Front View, Inc.

Gabelnick, F., MacGregor, J., Mathews, R. S., Smith, B. L.(1990). Learning communities: Creating connections among students, faculty, and disciplines. New Directions for Teaching and Learning, No.41. San Francisco, CA: Jossey-Bass.

Gaff, J. G. (1991). New life for the college curriculum: Assessing achievements and furthering progress in the reform of general education. San Francisco, CA: JosseyBass.

Gianini, P., \& Sarantos, S. T. (1995). Academic rhetoric versus business reality. In J. Roueche, K. Taber, \& S. Roueche (Eds.), The company we keep (pp. 203-206). Washington DC: Community College Press.

Kolb, D. (1984). Experiential learning. Englewood Cliffs, NJ: Prentice Hall.

O'Banion, T. (1997). A learning college for the 21" century. Phoenix, AZ: American Council on Education \& Oryx Press.

WIDS instructional designer. (1997). Waunakee, WI: Wisconsin Technical College System Foundation. [Computer Software]. 


\section{Contacts:}

Patrick Nellis

Coordinator, Faculty Development

East Campus, 5-220, MC 3-21

Valencia Community College

Orlando, FL 32825

(407) $299-5000 \times 2416$

(407) 382-2061 (Fax)

Email:Pnellis@gwmail.valencia.cc.fl.us

Helen Clarke

English Professor

Communications Department

Valencia Community College-East Campus

Orlando, FL 32825

(407) 299-5000 x2273

Email: hclarke@valencia.cc.fl.us

Jacalyn DiMartino

Project Director, Title V Grant

Osceola Branch Campus

Valencia Community College

1800 Denn John Lane

Kissimmee, FL 34744

(407) 299-5000 x4165

Email: jdimartino@gwmail.valencia.cc.fl.us

David K. Hosman, Activity Director

Title III Grant for Faculty Development

Valencia Community College, West

P.O. Box 3028

Orlando, FL 32802

(407) $299-5000 \times 1303$

(407) $299-5000 \times 1984$ (Fax)

Email: Dhosman@valencia.cc.fl.us

Patrick Nellis has been working fulltime on faculty and curriculum development projects for six years at Valencia Community College. He feels very lucky to be part of an extraordinary team of intelligent, caring, and highly skilled faculty and staff. He studied political science at the University of California, Irvine, and teaches US government as an adjunct professor at Valencia. He remains interested in the connections between education and democracy and is therefore very pleased to be working in the community college setting where these 
concerns are a part of everyday life. He loves the ocean and surfs when he gets the chance.

Helen Clarke has been Professor of English at Valencia Community College since 1990 where she has also participated in a wide variety of faculty development efforts. Last year she was an activity coordinator for the College-Level Achievement Initiative and for the last eight years has coordinated Teaching Writing: A Process in Itself, a seminar series focusing on active and collaborative approaches that make teaching and evaluating writing more effective. She also conducts writing across the curriculum workshops for the college. She is currently designing a department-level seminar series for adjunct faculty. She thinks most clearly when gardening and running.

Jacalyn DiMartino was recently selected as Project Director for a Title V grant project. Her experience with faculty and curriculum development at many levels (middle school, high school, and college) spans many years. Also, she has taught mathematics for over 20 years. Her interests include music and travel.

David K. Hosman has been on the management team of three major Title III grants, all supporting faculty development at Valencia Community College. He is the former Director of the Student Success Program at Valencia, and spent 16 years in Student Services. He is a licensed mental health counselor and is a regional consultant/trainer for the Faculty Development Division of the Houghton Mifflin Company. He enjoys golf, cycling, and playing with his grandchildren for relaxation.

\section{Appendix 9.1}

\section{PERFORMANCE-BASED INSTRUCTION (PBI) IN WISCONSIN INSTRUCTIONAL DESIGN SYSTEM (WIDS) FORMAT FOR THE CRITICAL THINKING COMPONENT}

Instructional Level Professional development

Target Population Faculty and staff at Valencia Community College

Description

A professional-level development program to understand, design, and implement improved critical thinking models with students at Valencia Community College.

\section{COMPETENCIES AND PERFORMANCE STANDARDS}

1) Redevelop curiosity Criteria performance will be satisfactory when:

and self-awareness

Domain-affective

level-internalization

Importanci-essential

Difficulty-medium a) you complete personality assessment: MBTI

b) you complete learning style assessment: Kolb ISI

c) you articulate reaction to and implications of selfawareness for intellectual curiosity

d) you articulate the importance of personality and learning style to student learning 


\section{Conditions for assessment:}

a) submission of completed assessments (MBTI and Kolb LSI) prior to workshop

b) format for reaction/implications statement from following choices: oral, video, written

c) in-workshop, and/or out-of-workshop assignments

d) group and/or individual activities

\section{Learning objectives:}

a) describe your personality style via MBTI

b) describe your learning style via Kolb LSI

c) reflect on where the excitement in learning comes from [intrinsic motivation]

2) Evaluate selected theories about knowledge acquisition Domain-cognitive Level-evaluation Importance-essential Difficultly-high
3) Identify stages of critical thinking Domain-cognitive Level-analysis Importance-essential Difficulty-high
Criteria performance will be satisfactory when:

a) you explain Bloom's taxonomy, with all six clements present

b) you summarize Kuhn's theories

c) you present an example of a paradigm of knowledge

d) you articulate the importance of a construction of knowledge perspective to student learning

\section{Conditions for assessment:}

a) choices of presentation format: oral, video, written

b) in-workshop, and/or out-of-workshop assignments

c) group and/or individual activities

Learning objectives:
a) list and explain Bloom's taxonomy
b) interpret Kuhn's history of science
c) paraphrase the concept of paradigm
d) defend a construction of knowledge perspecti

Criteria performance will be satisfactory when:

a) you create a concept map of a critical thinking stage model

b) your concept map has at least four stages and includes transition points

c) you articulate connections among models presented in workshop

d) you discuss relevance of stage models of critical thinking to classroom practices

Conditions for assessment:

a) choices of presentation format: oral, video, written

b) in-workshop, and/or out-of-workshop assignments

c) group and/or individual activities

Learning objectives:

a) describe Perry's stage model

b) contrast Belenky stage modcl with Perry's

c) paraphrase Nelson's version of stages

d) detail Nelson's guide to transitions

e) describc Novak's concept mapping techniques 
4) Identify ways of knowing (epistemology) within your discipline Domain-cognitive Level-synthesis Importance-essential Difficully-medium

5) Explain how practitioners "do" Domain-cognitive Level-application Importance-essential Difficulty-high
6) Create and sell your rationale for critical thinking
Criteria performance will be satisfactory when:

a) you provide examples of ways of knowing within your discipline

b) you compare/contrast your examples to ways of knowing in other disciplines

c) you relate personality and learning style to the dominant ways of knowing in your discipline

d) you relate knowing how to know in your discipline to course design, student learning, and or development advising

\section{Conditions for assessment:}

a) choices of presentation format: oral, video, written

b) in-workshop, and/or out-of-workshop assignments

c) group and/or individual activities

\section{Learning objectives:}

a) examine different ways of perceiving understanding

b) identify structure of knowledge in higher education

c) compare/contrast ways of knowing within your discipline to those of other disciplines

d) identify Kolb LSI relationship to academic disciplines

Criteria performance will be satisfactory when:

a) you relate an example of how knowledge is built in your discipline

b) you present a solution to a major problem discipline

c) you describe an area of meaningful ambiguity (where experts disagree and no certain answer exists) in your discipline.

d) you create a concept map of procedures for solving/ knowing in your discipline

e) you describe elements of course design that model procedures of your discipline

\section{Conditions for assessment:}

a) choices of presentation format: oral, video, written

b) in-workshop, and/or out-of-workshop assignments

c) group and/or individual activities

\section{Learning Objectives:}

a) describe prominent contributions to the knowledge base in your discipline

b) tell how to solve a problem in your discipline

c) identify areas of meaningful ambiguity (where experts disagree and no certain answer exists in your discipline

d) justify procedures of knowing in your discipline

e) explain connections between what you do in your discipline and what you do in your class

Criteria Performance will be satisfactory when:

a) rationale includes importance of critical thinking to your course and discipline 
Domain-cognitive

Level-synthesis

Importance-essential

Difficulty-high
7) Adapt a model of critical thinking to your discipline Domain-cognitive Level-synthesis Importance-essential Difficulty-high
8) Assess the effectiveness of your critical thinking model Domain-cognitive Level-evaluation Importance-essential b) rationale includes statement of importance of critical thinking outside of course and school contexts

c) rationale is research-based

d) you communicate rationale to students and colleagues Conditions for assessment:

a) rationale is clearly reflected in course syllabus assignments, and activities (as verified by peer assessment)

b) rationale is communicated in classrooms, departmental meetings, conferences, etc.

Learning objectives

a) research critical thinking literature related to your discipline

b) defend the role of critical thinking in your course and discipline

c) explain the role of critical thinking skills (general and discipline specific) outside of the academic context

d) internalize and model critical thinking behaviors

e) adjust presentation to audience

Criteria Performance will be satisfactory when:

a) model includes developmental (stage) framework

b) model provides step-by-step process for learners

c) model includes appropriate levels of challenge and support for student progress

d) model includes methods of transition to higher levels of cognition for learners

e) model embodies procedures of your discipline

f) model addresses different learning styles

g) you create a concept map for your model

h) you explain how to integrate model into classroom

Conditions for assessment:

a) model is peer assessed in workshop context by colleagues within your discipline

Learning objectives:

a) identify areas of your course(s) that are challenging to students

b) identify means to support students to meet the challenges of your course

c) choose/develop appropriate materials and activities

d) integrate critical thinking model into course design/ curriculum

Criteria performance will be satisfactory when:

a) you measure student engagement in the learning process

b) measurement indicates level of student thinking, interest, involvement, and understanding

c) you share results (feedback) from the measurement with students at next meeting 
Difficulty-high

9) Develop an implementation plan for your model of critical thinking Domain-cognitive Level-application Importance-essential Difficulty-medium d) measurement includes student self-assessments

e) results of assessment are used in refinement/redesign of model

Conditions for assessment:

a) using a Classroom Assessment Technique (CAT)

b) CAT designed to capture relevant information about student thinking in relation to model

c) CAT to be used immediately following learning activity

d) data from CAT to be summarized. into a format that can be shared with both students and colleagues

Learning objectives:

a) correlate assessment strategies to goals of the model

b) establish methods to monitor or measure student involvement/participation

c) process assessment results with students

d) develop, select, implement, and process student selfassessment

e) revise critical thinking model as appropriate

Criteria performance will be satisfactory when:

a) you apply model to (a) specific course(s)

b) you measure student performance (growth) in critical thinking

c) you report on results of this approach

Conditions for assessment:

a) implementation plan is peer assessed within workshop context

Learning objectives:

a) choose, develop assessment strategies and instruments

b) discuss logistics of implementation

c) employ cycle of classroom experimentation, feedback, evaluation, and revision

d) share findings as appropriate 